

\section{NOTICE}

The submitted manuscript has been offered by an employee of the Midwest Research Institute (MRI), a contractor of the US Government under Contract No. DE-AC36-99G010337. Accordingly, the US Government and MRI retain a nonexclusive royalty-free license to publish or reproduce the published form of this contribution, or allow others to do so, for US Government purposes.

This report was prepared as an account of work sponsored by an agency of the United States government. Neither the United States government nor any agency thereof, nor any of their employees, makes any warranty, express or implied, or assumes any legal liability or responsibility for the accuracy, completeness, or usefulness of any information, apparatus, product, or process disclosed, or represents that its use would not infringe privately owned rights. Reference herein to any specific commercial product, process, or service by trade name, trademark, manufacturer, or otherwise does not necessarily constitute or imply its endorsement, recommendation, or favoring by the United States government or any agency thereof. The views and opinions of authors expressed herein do not necessarily state or reflect those of the United States government or any agency thereof.

Available electronically at http://www.osti.gov/bridge

Available for a processing fee to U.S. Department of Energy and its contractors, in paper, from:

U.S. Department of Energy

Office of Scientific and Technical Information

P.O. Box 62

Oak Ridge, TN 37831-0062

phone: 865.576.8401

fax: 865.576 .5728

email: mailto:reports@adonis.osti.gov

Available for sale to the public, in paper, from:

U.S. Department of Commerce

National Technical Information Service

5285 Port Royal Road

Springfield, VA 22161

phone: 800.553 .6847

fax: 703.605.6900

email: orders@ntis.fedworld.gov

online ordering: http://www.ntis.gov/ordering.htm 
ISEC2006-99167

\title{
FIELD SURVEY OF PARABOLIC TROUGH RECEIVER THERMAL PERFORMANCE
}

\author{
Henry Price, Russell Forristall, Timothy Wendelin, Allan Lewandowski \\ National Renewable Energy Laboratory \\ Golden, Colorado
}

\author{
Timothy Moss \\ Sandia National Laboratories \\ Albuquerque, New Mexico
}

\author{
Carin Gummo \\ Apple Valley, California
}

\begin{abstract}
This paper describes a technique that uses an infrared (IR) camera to evaluate the in-situ thermal performance of parabolic trough receivers at operating solar power plants. The paper includes results to show how the glass temperature measured with the IR camera correlates with modeled thermal losses from the receiver. Finally, the paper presents results of a field survey that used this technique to quickly sample a large number of receivers to develop a better understanding of how both original and replacement receivers are performing after up to 17 years of operational service.
\end{abstract}

\section{INTRODUCTION}

During the period of 1984 to 1990, Luz International Limited built nine large solar power plants, $14 \mathrm{MW}$ to $80 \mathrm{MW}$ in size, in the California Mojave Desert [1]. These plants, referred to as Solar Electric Generating Systems or SEGS, have continued in daily operation and remain the largest solar power plants in the world today. During this period, these plants have demonstrated impressive operational availability and have sustained a high level of solar performance. These plants utilize a large field of parabolic trough solar collectors to heat a thermal fluid that is in turn used to generate steam to power a conventional steam Rankine cycle power plant. For this application, the parabolic trough solar field must operate at temperatures of $293^{\circ} \mathrm{C}$ to $391^{\circ} \mathrm{C}$. As a result, the long-term performance of the linear parabolic trough receiver, a fourmeter long stainless steel pipe coated with a solar selective coating and enclosed by an evacuated glass envelope, becomes one of the keys to achieving good sustained performance.

\section{BACKGROUND}

The parabolic trough linear receiver, also called a heat collection element (HCE), is one of the primary reasons for the high efficiency of the Luz parabolic trough collector design. The HCE consists of a four meter long, 70-mm outside diameter (O.D.) stainless steel tube with a cermet solarselective absorber surface, surrounded by an antireflective (AR) evacuated glass tube with a $115 \mathrm{~mm}$ O.D. (Figure 1). The HCE incorporates conventional glass-to-metal seals and metal bellows to achieve the necessary vacuum-tight enclosure and to accommodate for thermal expansion difference between the steel tubing and the glass envelope. The vacuum enclosure serves primarily to significantly reduce heat losses at high operating temperatures and to protect the solar-selective absorber surface from oxidation. The vacuum in the HCE, which must be at or below the Knudsen gas conduction range to mitigate convection losses within the annulus, is typically manufactured at about $1 \times 10^{-4}$ torr $(0.013 \mathrm{~Pa})$. The multilayer cermet coating is sputtered onto the steel tube to result in excellent selective optical properties with high solar absorptance of direct beam solar radiation and a low thermal emittance at operating temperature to reduce thermal reradiation. The outer glass cylinder has an AR coating on both surfaces to reduce Fresnel reflective losses from the glass surfaces, thus maximizing the solar transmittance. Getters, which are metallic compounds designed to absorb gas molecules, are installed in the vacuum space to absorb hydrogen and other gases that permeate into the vacuum annulus over time. The receivers include an evaporable barium getter that is used to monitor the vacuum in the receiver. The barium getter will have a silver appearance when the receiver has good vacuum, but will turn white if the receiver loses vacuum and is exposed to air. Because of the higher operating temperatures at the latest plants, substantial thermal decomposition of the heat transfer fluid is expected, and as a result, hydrogen buildup in the vacuum becomes more of a 
concern. In addition to getters, Luz developed a special hydrogen removal (HR) membrane made from a palladium alloy to help remove excess hydrogen from the vacuum annulus [2]. Unfortunately, a number of receiver reliability problems were experienced when receivers with the HRs were first used [3]. As a result, the HR was eliminated from the design on replacement receivers.

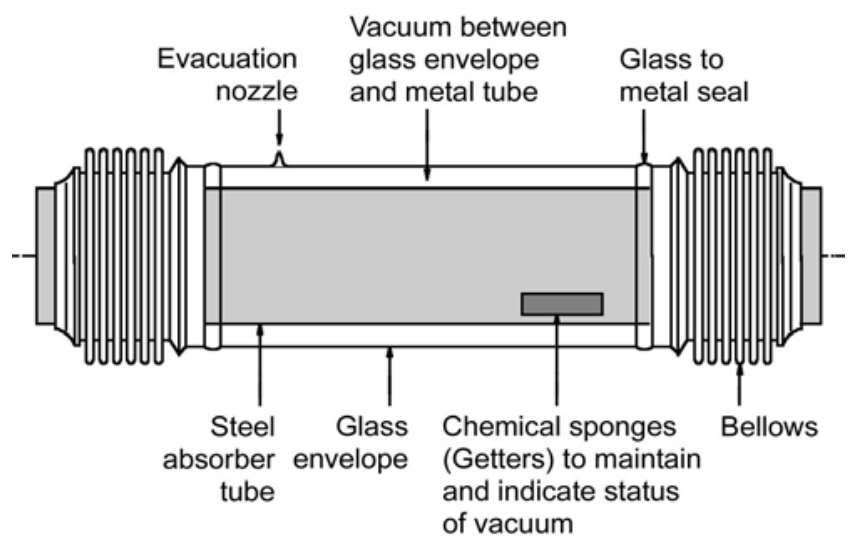

Figure 1. Heat collection element (HCE) (Source: Flabeg Solar International)

Although Luz went out of business in 1991, two new companies are supplying parabolic trough receivers for replacements at existing plants and for new plants. Solel Solar Systems $^{1}$ of Israel took over the Luz receiver manufacturing facility and has continued to improve the receiver design and performance [3]. Schott Glass of Germany ${ }^{2}$ has also recently developed a new receiver design that it sells commercially [1].

The thermal performance of parabolic trough receivers has been tested by a number of sources. Dudley et al [4] tested the original Luz cermet and black chrome receivers on an LS-2 collector mounted on the rotating platform at the National Solar Thermal Test Facility in Albuquerque, New Mexico. The Sandia test results provide a performance baseline for the original Luz receivers in new condition. Solel developed a new parabolic trough receiver to improve reliability issues with the glass to metal seal and to improve the durability and properties of the selective coating. The relative thermal performance of these receivers was measured in a test loop of collectors at the SEGS VI and compared with original Luz receivers operating in a parallel loop of collectors [3]. The test was conducted at SEGS VI plant because it uses the optically superior LS-2 collector and it operates up to $391{ }^{\circ} \mathrm{C}$. Although a significant increase in performance of 20 to 30 percent was observed with the new Solel receivers, it was not determined whether the increased performance was entirely a result of improvements in the new receiver, or caused, in part, by degradation of the original receivers. Sandia has subsequently tested the new receivers from both Solel and Schott on the rotating platform

\footnotetext{
${ }^{1}$ Solel Solar Systems, Ltd., Jeruslam, Israel, www.solel.com.

${ }^{2}$ Schott Glass, Mainz, Germany, www.schott.com/solar.
}

[5]. These tests indicate that the new receivers do show significantly improved performance, however, not the 20 to 30 percent seen in the loop tests at SEGS VI. In general, there has been extensive testing of new receiver performance, but there has been very little done to look at the thermal performance of receivers after they have been in service for many years. This paper looks at a new approach for evaluating the in-situ thermal losses of parabolic trough receivers in an operating solar plant.

\section{METHODOLOGY}

The modular nature of a parabolic trough power plant allows periodic maintenance on individual collectors while the rest of the plant continues to operate. A single collector can be defocused for mirror replacement, optical alignments, or electronic repairs, while hot fluid continues to pass through the receivers. The glass envelope temperature on receivers with good vacuum remain reasonably cool (approximately $70^{\circ} \mathrm{C}$ to $100^{\circ} \mathrm{C}$ ), even when heat transfer fluid at operating temperatures is flowing through them (on the non-tracking collector). When receivers lose vacuum, e.g. air gets into the annulus between the steel and glass tubes, the temperature of the glass increases significantly. The maintenance crews know to be careful around receivers that have lost vacuum because they represent a potential burn hazard if touched with bare skin. Receivers that have lost vacuum are generally easy for crews to identify because the barium detector getter turns white when exposed to air. Several years ago, the maintenance crews began noticing that the glass temperature was elevated on some receivers that otherwise still appeared to have good vacuum. Field inspections showed that some receivers that still appeared to have good vacuum actually had glass temperatures above those that had lost their vacuum. When a hole was drilled through the bellows of one of these receivers, air was observed to be sucked into the annulus. The glass temperature then cooled off to that of a receiver with air in the annulus. Based on this behavior, the hot receivers appeared to be showing signs of a build-up of hydrogen in the vacuum annulus. The hydrogen is assumed to come from decomposition of the heat transfer fluid (HTF) which is permeating through the stainless steel tube into the vacuum annulus.

In 2005, FPL Energy, the operating company of the SEGS III-IX plants requested support from SunLab $^{3}$ to conduct a survey of the solar fields to try to assess the extent of receivers experiencing the hot glass behavior.

\footnotetext{
${ }^{3}$ SunLab is a partnership between Sandia National Laboratories and the National Renewable Energy Laboratory. The labs work together as one virtual laboratory to support DOE's research and development efforts in Concentrating Solar Power.
} 


\section{Modeling of Receiver Thermal Losses}

A model has been developed by Forristal [6] based on an approach developed by Mancini in Dudley et al [4], to predict the thermal performance of parabolic trough receivers. The model was developed to assess the trade-offs of different designs and properties of materials used in the receiver for a range of operating and ambient conditions. The model can also account for different levels of vacuum and gas compositions in the annulus. Figure 2 shows the modeled thermal losses of a new Solel Universal Vacuum Receiver (UVAC) based on properties reported in [3] with good vacuum at $1 \times 10^{-4}$ torr, and receivers with different pressures of air, hydrogen and helium in the annulus space. The figure shows losses for a one-meter length of the receiver with a fluid temperature of $350^{\circ} \mathrm{C}$. If the receiver loses vacuum and air enters the annulus the pressure in the annulus will be atmospheric (approximately 760 torr). If hydrogen permeates into the vacuum space through the steel tube from the HTF, and the getters or HR are not able to adsorb or remove it, then the hydrogen pressure can build up until it is at equilibrium with the partial pressure of hydrogen in the HTF. The rate at which hydrogen migrates depends on many factors including the temperature and properties of the steel tube, and the partial pressure of hydrogen in the HTF. Limited data currently exists on the partial pressure of hydrogen in the HTF, but we believe it is about 1 torr at the plants experiencing the hot glass problem. Figure 2 shows that a loss of vacuum in the receiver doubles thermal losses, and hydrogen in the annulus can cause thermal losses to be almost four times that of a receiver with good vacuum.

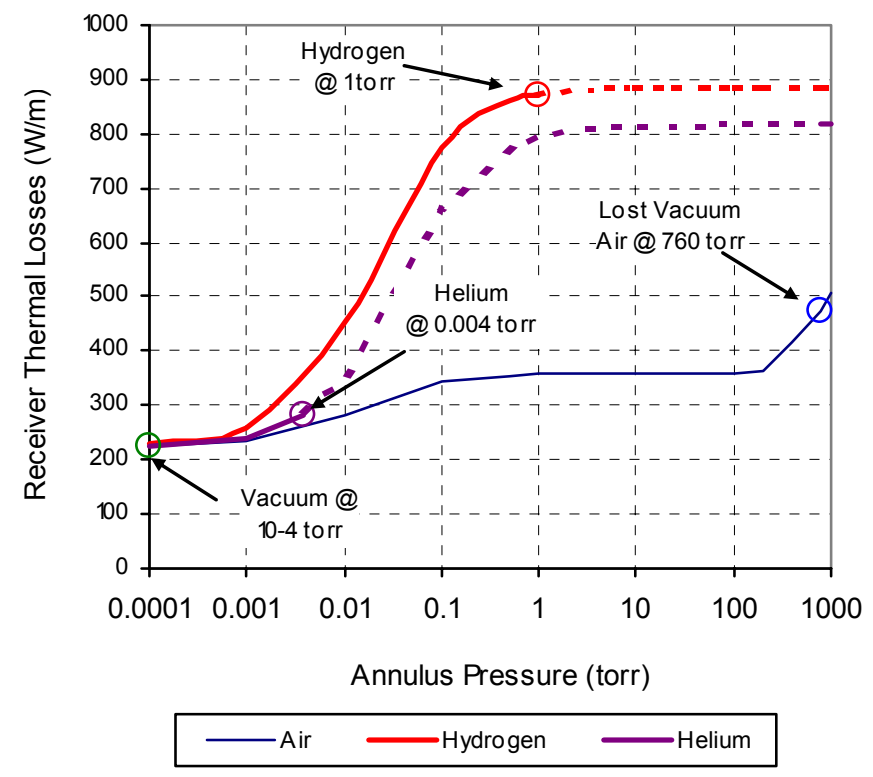

Assumes: LS-2 collector with new Solel UVAC cermet receiver, Therminol VP-1 heat transfer fluid @ $350^{\circ} \mathrm{C}, 140$ gpm, DNI 950 $\mathrm{W} / \mathrm{m}^{2}$, wind speed $1 \mathrm{~m} / \mathrm{s}, 35^{\circ} \mathrm{C}$ ambient temperature .

Figure 2. Receiver Thermal Losses
Experience from evacuated glass tubular solar water heating collectors has shown that helium from the atmosphere can diffuse through the glass into the vacuum over time. Harding [7] found that the time it takes the helium pressure in the vacuum to come to equilibrium with the partial pressure of helium in the atmosphere ( 0.004 torr) depends on the type and temperature of the glass. In the water heating case, borosilicate evacuated tubes at $100^{\circ} \mathrm{C}$ took 6 years and tubes at $400^{\circ} \mathrm{C}$ took only 3 months to reach equilibrium pressure. Because parabolic trough receivers use borosilicate glass, it is likely that helium permeates into the vacuum annulus over time. Figure 2 also shows the effect on thermal losses as helium from the atmosphere permeates into the vacuum space. The circle on the helium line represents the partial pressure of helium in the atmosphere. Helium in the vacuum annulus at equilibrium with helium in the atmosphere would increase thermal losses by about $20 \%$ over a receiver with vacuum at $10-4$ torr.

Figure 3 shows how receiver thermal losses vary as a function of HTF temperature and receiver annulus condition. It can be seen that helium causes a slight increase in thermal losses, but not nearly as significant as air or hydrogen in the annulus. The receiver model can also be used to determine the glass envelope temperature. Figure 4 shows the temperature of the glass envelope for the same cases shown in Figure 3. From Figure 4, it is clear that glass temperatures are elevated when receivers lose vacuum, or if hydrogen builds up in the annulus.

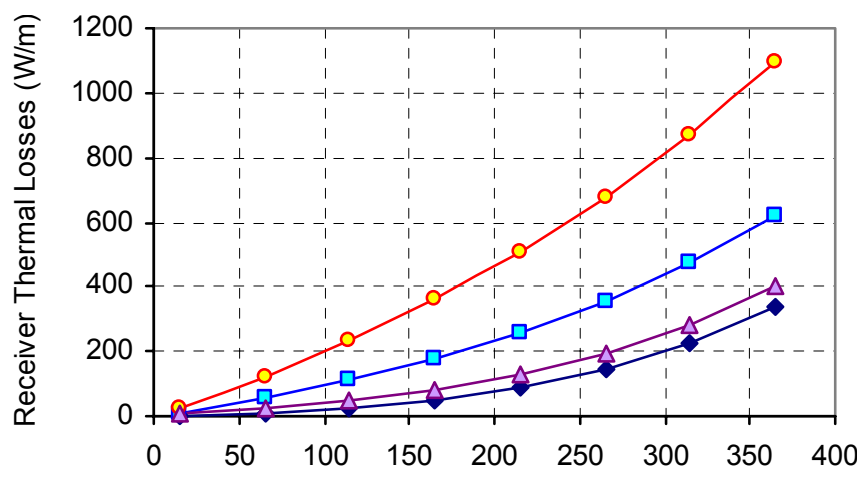

Heat Transfer Fluid - Ambient Air Temperature (C)

\begin{tabular}{ll|}
$\longrightarrow-$ Vac & $-\square-$ Air @ 760 torr \\
$\multimap-\mathrm{H} 2$ @ 1 torr & $-\triangle$ He @ 0.004 torr \\
\hline
\end{tabular}

Figure 3. Receiver Thermal Losses as a Function of Fluid Temperature and Annulus Condition 


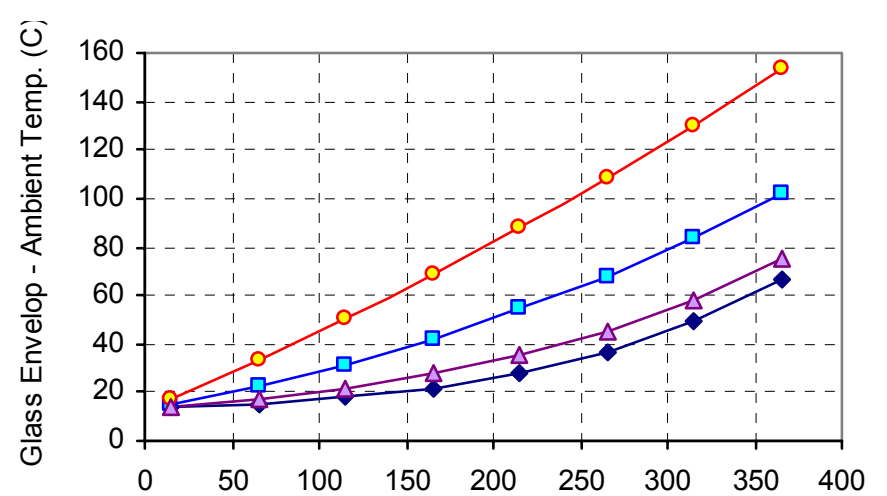

Heat Transfer Fluid - Ambient Air Temperature (C)

$\neg-$ Vac $\square-A i r \multimap-\mathrm{H} 2 @ 1$ torr $\neg-\mathrm{He} @ 0.004$ torr

Figure 4. Receiver Glass Temperature as a Function of Fluid Temperature and Annulus Condition

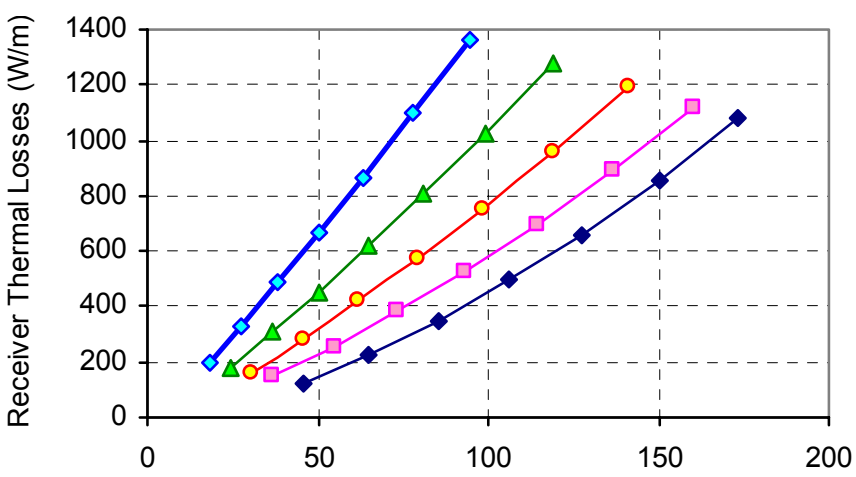

Glass Envelop - Ambient Air Temperature (C)

$\neg 0 \mathrm{~m} / \mathrm{s} \multimap \square-1 \mathrm{~m} / \mathrm{s} \multimap-2 \mathrm{~m} / \mathrm{s} \multimap \triangle 4 \mathrm{~m} / \mathrm{s} \multimap 8 \mathrm{~m} / \mathrm{s}$

Figure 5. Receiver Thermal Losses as a Function of Glass Temperature and Wind Speed

Because the receiver glass envelope is essentially opaque to infrared (IR) energy, all the thermal losses from the receiver must pass, via conduction, through the glass envelope. As a result, the radiant and convective thermal losses from the receiver are directly related to the glass envelope temperature, and it does not matter what is happening inside the glass tube (for example, the type and quality of the selective coating, whether the vacuum is good or bad, or the HTF fluid temperature). The thermal losses can be correlated directly with the glass envelope temperature for known air temperature and wind speed. Figure 5 shows receiver thermal losses as a function of glass envelope temperature for known wind velocities and an air temperature of $35^{\circ} \mathrm{C}$. Figure 5 becomes a very useful tool for evaluating the relative thermal performance of receivers in the solar field.
One problem with Figure 5 is that the model assumes the wind direction is perpendicular to the receiver. In practice, the wind velocity near the receiver is not measured, and the influence of the wind direction being non-perpendicular to the receiver has not been determined. To complicate matters, at the existing plants the prevailing wind direction is from the west. As a result, the mirrors shelter the receiver from the wind in the morning, but the receivers are more exposed to the wind in the afternoon when the collectors face into the wind. It is clear from the figure that accurate estimates of the wind speed are needed to determine receiver thermal losses.

\section{Receiver Field Survey}

The operators of the SEGS plants developed a procedure for measuring receiver glass temperature. The procedure required collectors to be defocused while measurements were taken on each receiver with a hand-held IR temperature measurement gun. The collector had to be defocused so that the crews were able to get close enough to take a measurement. The IR gun reads the temperature of a relatively small spot. Several readings were taken on each receiver to obtain a more representative average glass temperature. Although the operators have a database that is used to track failures and repairs in the solar field, the actual receiver type and year of manufacture is not tracked directly. Thus, a visual inspection of each receiver was required to identify this information. The approach allowed a 2-person crew to measure the glass temperature on about 200 receivers in a day.

At FPL Energy's request, NREL developed a new approach for measuring receiver temperatures using a solar blind IR camera. A ThermaCAM ${ }^{\mathrm{TM}}$ S40 IR camera and Researcher software (trademark of FLIR Systems) was used [8]. The camera operates in the far IR region $(8-14 \mu \mathrm{m})$ and is not affected by incident solar radiation (wavelengths $0.3-2 \mu \mathrm{m}$ ) on the glass envelope. As a result, the glass temperature can be measured while the collectors are tracking the sun.

Figure 6 shows an example of an IR image taken of a parabolic trough receiver. From the image, the receiver, receiver supports, mirrors, and sky are clearly identifiable. The color of the image represents the intensity of the IR signal and its temperature.

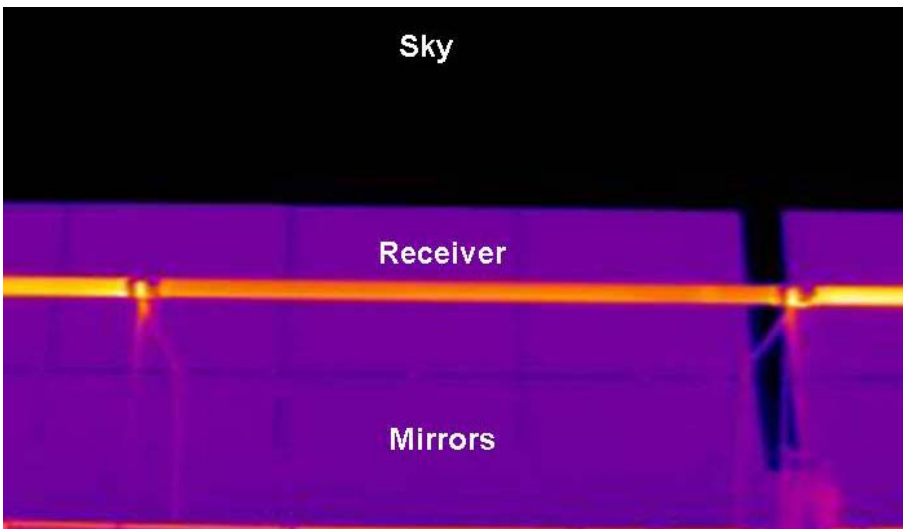

Figure 6. IR Camera Image of Parabolic Trough Receiver 
A custom Excel spreadsheet was developed that links directly to the ThermaCAM Researcher software to record IR images of the receiver, analyze the receiver image to determine its average temperature, and store the image on a laptop computer for any subsequent analysis that might be required. In addition, NREL developed a new data query methodology that used the FPL Energy field maintenance database to determine the type and year of manufacture of each receiver in the solar field. Detailed maps of receiver types and locations in the solar field were developed. During 2005, SunLab conducted several field surveys of receiver glass temperatures at six of the nine SEGS plant solar fields with the IR camera system. In total, the glass temperatures on over 12,000 receivers were measured using the IR camera technique. When the equipment was debugged, it was possible for two people to image up to 5000 receivers in a single day. A 30-MWe plant has approximately 10,000 receivers.

The IR camera measures the emitted IR radiation from an object. Because the emitted radiation is a function of the surface temperature of the object, the temperature of the surface can be determined if the emittance of the surface is known. The signal measured by an IR camera must also be corrected for attenuation by the atmosphere, emission of the atmosphere, and reflected emission from ambient sources. The camera accounts for both attenuation and emission from the atmosphere based on an assumed ambient temperature, relative humidity, and distance to the object. Reflected IR energy can also be a concern when the measured object is close in temperature to its surroundings. In this case, the receiver glass temperature that we are attempting to measure is generally significantly higher than the ambient and surrounding temperatures. It is possible that the reflected energy from the receiver supports and bellows shielding could affect the measured glass temperatures near the ends of the receivers.

The ThermaCAM Researcher Analysis Software was used to evaluate the IR images to determine the receiver glass temperatures. Figure 7 shows a typical example screen from the ThermaCAM software used to analyze the temperature of a receiver. Field measurements showed that the glass temperature varies significantly along both the length and cross-section of a single receiver. Therefore, the analysis software was used to evaluate ten temperature cross-sections on each receiver. The upper left corner of Figure 7 shows the ten cross-sections. The bottom half of the figure shows the temperature profile for each of the cross-sections. The temperature profiles assume the emittance of glass ( 0.85$)$ for the entire image.

For each cross-section, the maximum temperature is determined. This temperature is assumed to be the glass

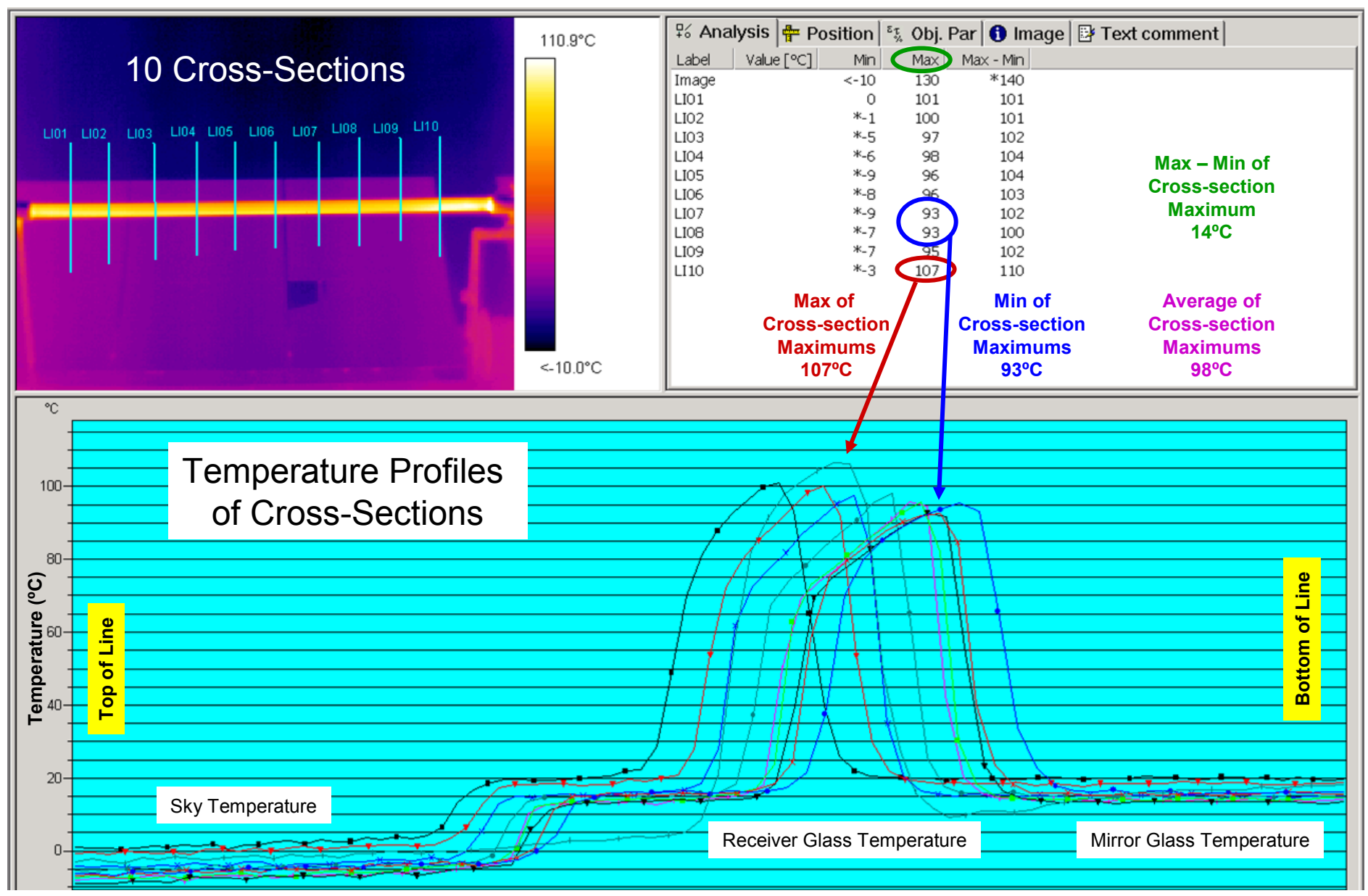

Figure 7. ThermaCAM Researcher Analysis Software 
temperature of the receiver at this cross section. The maximum value for each of the ten cross-sections is used to calculate average, maximum, and minimum glass temperatures for each receiver. The example in Figure 7 shows a calculated average glass temperature of $98^{\circ} \mathrm{C}$, maximum temperature of $107^{\circ} \mathrm{C}$, and a minimum temperature of $93^{\circ} \mathrm{C}$. It is also useful to evaluate the difference between the maximum and minimum temperature, in this case the difference is $14^{\circ} \mathrm{C}$.

To minimize the impact on the plant operations and performance, one of the goals of the new receiver assessment effort was to test the receivers while the collectors were tracking. It is important to note that the glass temperature will change depending on whether the collector is tracking the sun (i.e. concentrated light is focused on the glass and metal absorber) or not. This is because the absorber temperature is higher when light is focused on the receiver and also because the glass absorbs some of the light passing through it. To verify that reasonable results could be achieved with the collectors tracking, a number of receivers were tested twice. First while the collectors were tracking and again when they were not tracking. Figure 8 shows the glass envelope temperature for a new ( $\sim 2$ years old) Solel UVAC receiver when the HTF temperature is about $330^{\circ} \mathrm{C}$. The $\mathrm{HTF}$ temperature is estimated based on the inlet and outlet HTF temperatures for the loop of collectors being tested. At design conditions, the HTF temperature increases about $0.5^{\circ} \mathrm{C}$ across each receiver. In this case, the glass envelope is about $68^{\circ} \mathrm{C}-71^{\circ} \mathrm{C}$ when the collector is tracking and $63^{\circ} \mathrm{C}-66^{\circ} \mathrm{C}$ when the collector is not tracking. The UVAC shows only a minor temperature variation along the length of the receiver, about $3^{\circ} \mathrm{C}$. In addition, there was only a small increase of about $5^{\circ} \mathrm{C}$ in glass temperature between the non-tracking and tracking measurements. This result is consistent with what would be expected based on modeled results.

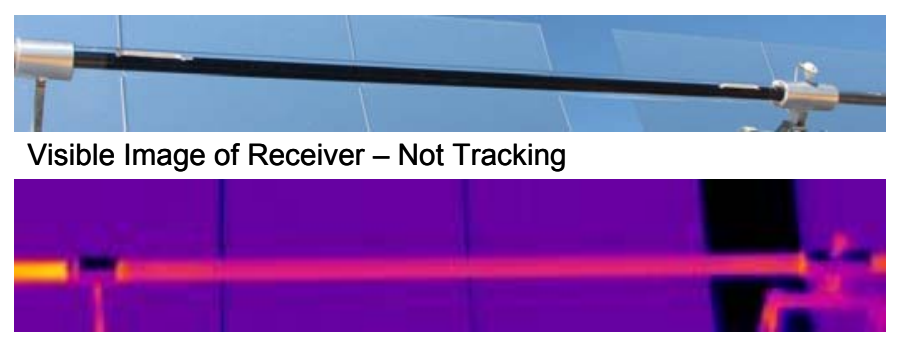

Infrared Image - Not Tracking (Glass Temp. $63^{\circ} \mathrm{C}-66^{\circ} \mathrm{C}$ )

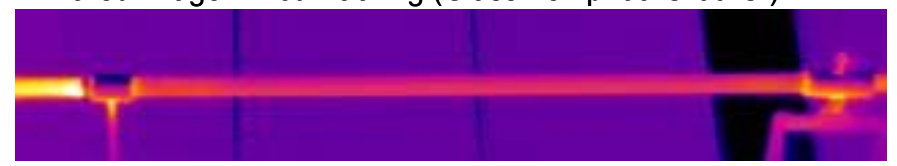

Infrared Image - Tracking (Glass Temp. $68^{\circ} \mathrm{C}-71^{\circ} \mathrm{C}$ )

\section{Figure 8 New Solel UVAC Receiver with Getters}

Figure 9 shows an example of one of the original Luz cermet receivers at SEGS VI that has been in service for 17 years. The receiver visually appears to be in good condition, and the barium getter indicates good vacuum. The receiver is also operating with $\mathrm{HTF}$ at approximately $330^{\circ} \mathrm{C}$. However, the glass temperature is significantly higher than the UVAC receiver. This is due in part to the higher emittance of the original Luz cermet coating relative to the new Solel UVAC selective coating. The temperature variation along the tube is also significantly greater, almost $130^{\circ} \mathrm{C}$. On inspection, it can be seen that many of the older receivers have metallic dust from getter decomposition inside the glass tubes. When the collector is tracking, concentrated sunlight heats the dust, which in turn causes localized heating of the glass envelope. The hot spots in Figure 9 are of concern, but are not related to the hydrogen problem being investigated. Care must be taken to make sure the getter dust problem does not corrupt the search for receivers with hydrogen build-up. In general, receivers with the hydrogen buildup will have a higher minimum temperature and may or may not also suffer from the getter dust problem. It was decided to use the minimum crosssection temperatures to evaluate the condition of the receiver vacuum.
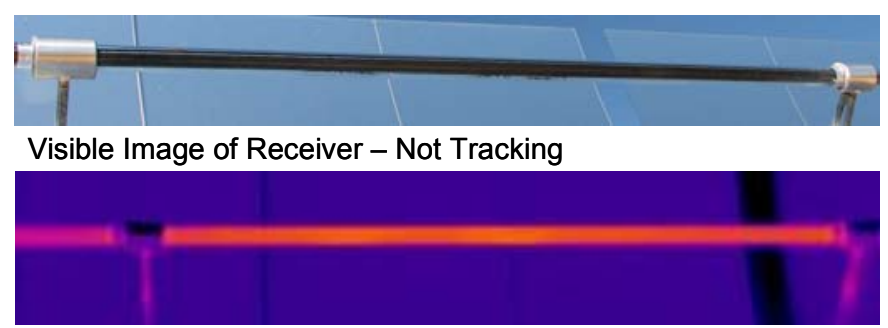

Infrared Image - Not Tracking (Glass Temp. $124^{\circ} \mathrm{C}-141^{\circ} \mathrm{C}$ )

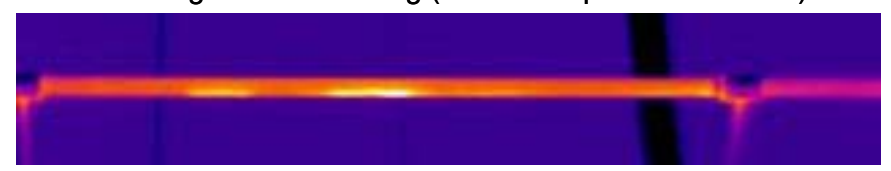

Infrared Image - Tracking (Glass Temp. $138^{\circ} \mathrm{C}-267^{\circ} \mathrm{C}$ )

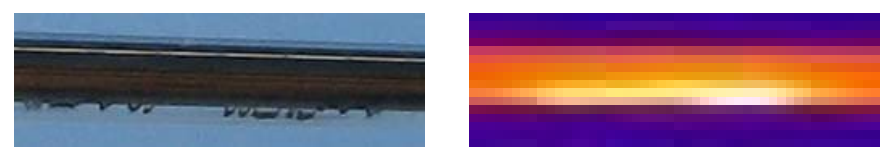

Getter dust is causing hot spots on the glass

Figure 9. Original Luz Cermet Receiver with HR \& Getters

The glass temperatures measured with the IR camera were independently measured on several receivers with a stick on Type $\mathrm{T}$ thermocouples (accuracy is $1^{\circ} \mathrm{C}$ or $0.75 \%$ of reading, whichever is greater) attached to the glass. IR camera measurements were within $2^{\circ} \mathrm{C}$ to $6^{\circ} \mathrm{C}$ of the thermocouple temperature measurement, depending on whether the collectors were tracking or not. 


\section{RESULTS}

A field survey was conducted with the IR camera of the southwestern quadrant of the SEGS VI solar field. There are three types of receivers installed at SEGS VI. The plant initially had Luz black chrome receivers on the cold half of the collector loops, and Luz cermet receivers on the hot side of the collector loops. The black chrome receivers used getters only. The cermet receivers had the HR membranes and some getters. The third type of receiver present is a replacement cermet receiver. These have getters but no HR membranes. Figure 10 shows the glass envelope temperature (minus ambient air temperature) as a function of HTF temperature (minus ambient air temperature) for each receiver surveyed. Receivers that have lost vacuum, have coating failures, or have the glass envelope broken are not shown.

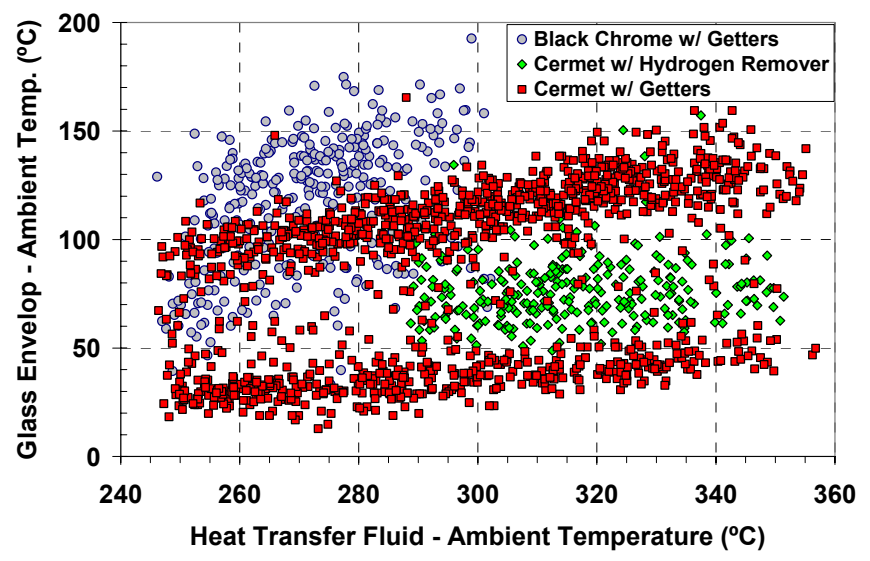

Figure 10. SEGS VI Receiver Survey Results

The SEGS VI testing shows some interesting results. The replacement cermet receivers with just getters show distinct low- and high-temperature bands. The receivers in the lower band represent receivers performing as expected based on testing of new receivers at Sandia. The upper band represents receivers that show signs indicative of hydrogen build-up in the vacuum annulus. The solar field receiver database was used to identify the receivers in each band. The receivers in the lower band are typically the latest UVAC generation with up to four times the getter material, and with the getters mounted off the absorber to keep them cool and increase their hydrogen absorption capacity. It is interesting to note that the optical quality of the replacement receivers in both the upper and lower bands is typically excellent, and it is generally not possible to tell visually whether a receiver is hot.

The cermet receivers with the hydrogen remover are generally performing as expected even after 17 years of service. The glass temperature is generally higher than the best new replacement tubes, because the selective coating is not quite as good. There is more scatter in the temperature of these tubes, probably because variations in how well the hydrogen palladium membrane is working and variations in the quality of the selective coating. The palladium membranes work best when hot, however the O\&M company has shaded them to prevent failures of the glass envelope. Thus, the membranes may not be operating at their optimal temperature.

The black chrome receivers are generally performing worse than other receivers in the solar field. This is likely because of the higher thermal emittance of the black chrome selective coating and because the receivers use a relatively small amount of getters to handle hydrogen permeation.

\section{DISCUSSION}

The SunLab receiver model was used to evaluate the influence of receiver vacuum on receiver thermal losses and receiver glass temperature. The model showed that hydrogen build-up in the receiver annulus can result in substantial increase in receiver glass temperature. In addition, the model shows that receiver glass temperature provides a good indication of thermal losses from the receiver. Therefore, measurement of the envelope glass temperature provides a good measure of receiver performance.

The IR camera methodology presented here provides a useful technique for rapid evaluation of parabolic trough receivers in an operating solar field. A large number of receivers can be evaluated in a short period with the IR camera. Wind velocity has a significant effect on glass temperature, so it is important to do the measurements when there is very little wind.

The field-testing has helped identify that hydrogen buildup appears to be an issue in some receivers, but not others. The initial Luz cermet receivers with HR appear to be performing adequately without a noticeable buildup of hydrogen. However, a number of replacement receivers without the HR show signs of elevated glass temperature that is indicative of hydrogen build-up. Receiver vendors are addressing this issue with new designs that increase the hydrogen capacity of the getters. Schott Glass is also changing the composition of the steel tube and using additional hydrogen barrier coatings to reduce hydrogen permeation rates into the vacuum to increase the receiver lifetime.

Additional receiver testing is being conducted in controlled laboratory experiments on a new receiver thermal loss test stand at NREL. The testing will further explore the relationship between thermal losses and receiver glass envelope temperature as a function of receiver type and gas composition in the annulus. A new non-destructive instrument has been developed [9] to identify gas composition and pressures in the receiver vacuum annulus. Preliminary test results on a number of receivers removed from the solar field show that hydrogen is present in receivers that exhibit elevated glass temperatures. 


\section{ACKNOWLEDGMENTS}

This work has been conducted with funding from the U.S. Department of Energy's Solar Energy Technologies Program. We appreciate the technical and logistical support from FPL Energy the operator of the SEGS III-IX parabolic trough solar power plants.

\section{REFERENCES}

[1] Kearney, D., Price, H., "Advances in Parabolic Trough Solar Power Technology," Advances in Solar Energy. Vol 16, Kreith, F., Goswami, D.Y. (Eds.), ASES, Boulder, Colorado, 2005.

[2] Labaton, I., Y. Harats, "Hydrogen Pump," United States Patent 4,886.048, Dec. 12, 1989.

[3] Price, H., M. Hale, R. Mahoney, C. Gummo, R. Fimbres, R. Cipriani, "Development in High Temperature Parabolic Trough Receiver Technology," Proceeding of ISEC: Solar 2004, Portland, Oregon, July 11-14, 2004.

[4] Dudley, V. G. Kolb, A. R. Mahoney, T Mancini, C Matthews, M. Sloan, D. Kearney, "Test Results SEGS LS2 Solar Collector," SAND94-1884, December 1994.

[5] Moss, T., D. Brosseau, "Final Test Results for the Schott HCE on a LS-2 Collector," SAN2005-4034, Sandia National Laboratory, July 2005.

[6] Forristall, R., "EES Heat Transfer Model for Solar Receiver Performance," Proceedings of ISEC, Solar 2004, Portland, Oregon, July 11-14, 2004.

[7] Harding, G. L., "Helium Permeation in All-Glass Tubular Evacuated Solar Energy Collectors," Solar Energy Materials 5 (1981), pp. 141-147, North-Holland Publishing Company.

[8] FLIR Systems, "ThermaCAM ${ }^{\mathrm{TM}}$ Researcher Professional Edition," Version 2.8, web: www.flr.com.

[9] Latent Structures, "Spectral Evaluation Experiments of HCEs," NREL Subcontract ACO-5-55519-01, Boulder, CO, Feb-Mar 2006 


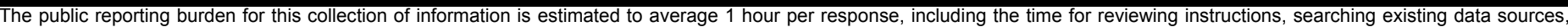

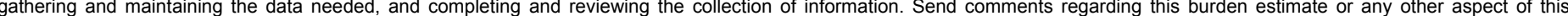

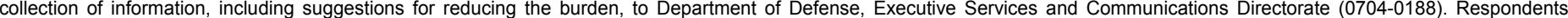

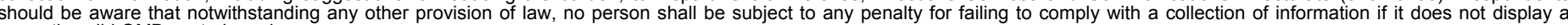
currently valid OMB control number.

PLEASE DO NOT RETURN YOUR FORM TO THE ABOVE ORGANIZATION.

\section{REPORT DATE (DD-MM-YYYY) April 2006 \\ 2. REPORT TYPE Conference Paper}

4. TITLE AND SUBTITLE

Field Survey of Parabolic Trough Receiver Thermal Performance: Preprint
3. DATES COVERED (From - To) 5a. CONTRACT NUMBER

DE-AC36-99-G010337

5b. GRANT NUMBER

5c. PROGRAM ELEMENT NUMBER

5d. PROJECT NUMBER

NREL/CP-550-39459

5e. TASK NUMBER

CP06.1001

5f. WORK UNIT NUMBER

7. PERFORMING ORGANIZATION NAME(S) AND ADDRESS(ES)

National Renewable Energy Laboratory

1617 Cole Blvd.

Golden, CO 80401-3393
8. PERFORMING ORGANIZATION REPORT NUMBER

NREL/CP-550-39459

9. SPONSORING/MONITORING AGENCY NAME(S) AND ADDRESS(ES)

10. SPONSOR/MONITOR'S ACRONYM(S) NREL

11. SPONSORING/MONITORING AGENCY REPORT NUMBER

\section{DISTRIBUTION AVAILABILITY STATEMENT}

National Technical Information Service

U.S. Department of Commerce

5285 Port Royal Road

Springfield, VA 22161

\section{SUPPLEMENTARY NOTES}

14. ABSTRACT (Maximum 200 Words)

This paper describes a technique that uses an infrared camera to evaluate the in-situ thermal performance of parabolic trough receivers at operating solar power plants.

\section{SUBJECT TERMS}

Concentrating solar power; parabolic solar trough; parabolic trough

\begin{tabular}{l}
\hline \multicolumn{3}{|l|}{ 16. SECURITY CLASSIFICATION OF: } \\
\hline \begin{tabular}{l|l|l|} 
a. REPORT & b. ABSTRACT & c. THIS PAGE \\
Unclassified & Unclassified & Unclassified \\
& & \\
\hline
\end{tabular} \\
\hline
\end{tabular}

17. LIMITATION
OF ABSTRACT
UL

18. NUMBER OF PAGES 19a. NAME OF RESPONSIBLE PERSON

19b. TELEPONE NUMBER (Include area code) 